\title{
Effect of baseline symptom severity on continence improvement mediated by oxybutynin chloride topical gel
}

This article was published in the following Dove Press journal:

Open Access Journal of Urology

18 October 2011

Number of times this article has been viewed

Peter K Sand'

Scott A MacDiarmid ${ }^{2}$

Heather Thomas ${ }^{3}$

Kim E Caramelli ${ }^{3}$

Gary $\mathrm{Hoel}^{3}$

'University of Chicago, Pritzker School of Medicine, Chicago, IL; ${ }^{2}$ Alliance Urology Specialists, Greensboro, NC; ${ }^{3}$ Watson Laboratories, Inc., Salt Lake City, UT, USA
Correspondence: Peter K Sand Evanston Continence Center, North Shore University Health System, University of Chicago, Pritzker School of Medicine, 1000 Central Street, Suite 730, Evanston, IL 6020I, USA

Tel + I 8475702750

Fax +I 847570 I386

Email psand@northshore.org
Background: In a recent placebo-controlled Phase III study, oxybutynin chloride topical gel (OTG) significantly improved urinary continence in patients with overactive bladder. In this post hoc analysis, the effect of incontinence severity on OTG-mediated improvement in continence was evaluated.

Methods: Change from baseline in the number of incontinence episodes was evaluated in patients with two to three incontinence episodes/day (moderate incontinence) and those with more than three incontinence episodes/day (severe incontinence).

Results: In patients with moderate $(n=171)$ and severe $(n=556)$ incontinence, reduction in incontinence episodes (mean \pm standard deviation) was greater $(P<0.01)$ with OTG (moderate, $-1.7 \pm 1.4$; severe, $-3.6 \pm 3.0$ ) than with placebo (moderate, $-1.2 \pm 1.3$; severe, $-3.1 \pm 3.4$ ). Continence achievement rate with OTG was $48.2 \%$ (placebo, $24.4 \%$ ) among patients with moderate incontinence and $17.8 \%$ (placebo, 12.1\%) among those with severe incontinence.

Conclusion: Absolute placebo-adjusted reduction in incontinence episodes with OTG was not affected by baseline incontinence severity. Continence achievement was more likely if symptoms were less severe.

Keywords: incontinence, overactive bladder, oxybutynin chloride topical gel, continence

\section{Introduction}

Overactive bladder syndrome is defined by the International Urogynecological Association and the International Continence Society as urinary urgency, usually accompanied by frequency and nocturia, with or without urgency urinary incontinence, in the absence of urinary tract infection or other obvious pathology. ${ }^{1}$ Estimates of overactive bladder prevalence in the US are $16.9 \%$ in women and $16.0 \%$ in men. ${ }^{2}$ The symptoms of overactive bladder, including incontinence, negatively affect healthrelated quality of life. .,3 $^{2,}$

Oxybutynin, an antimuscarinic agent, is commonly used to treat overactive bladderrelated symptoms. ${ }^{4}$ Oxybutynin chloride topical gel (OTG) is a transdermal formulation that consists of a clear gel containing $10 \%$ oxybutynin. One gram of the gel is applied topically once daily in a small dosing volume (approximately $1 \mathrm{~mL}$ ). Results of a 12-week Phase III study demonstrated that OTG, compared with placebo, significantly reduced the number of daily incontinence episodes, decreased urinary frequency, and increased voided volumes in adults with overactive bladder. ${ }^{5}$ In the study, OTG had an excellent safety profile, which was characterized by low incidences of anticholinergic adverse effects and application site skin reactions. ${ }^{5}$ 
The number of incontinence episodes per day is a measure of overactive bladder symptom severity ${ }^{6,7}$ that correlates with patients' perception of bladder condition. ${ }^{8}$ When using a single-item global measure of patient perception of bladder condition, Coyne et al found that the mean number of incontinence episodes/day was 2.0 for patients who perceived their bladder condition as moderate and 3.3 incontinence episodes/day for those who perceived it as severe. ${ }^{8}$ Here we present results of a post hoc analysis of the OTG Phase III study $^{5}$ that evaluated the effect of incontinence severity on OTG-mediated improvement in continence.

\section{Materials and methods}

This is a retrospective subgroup analysis of the Phase III US study of OTG in patients with overactive bladder. The design and main results of this multicenter, randomized, double-blind, placebo-controlled study (NCT00350636) have been published. ${ }^{5}$

\section{Patients and treatments}

Study participants were men and women aged $\geq 18$ years with urgency urinary incontinence or urgency-predominant mixed urinary incontinence, an average of at least eight urinary voids per day, and at least four urge incontinence episodes during a three-day baseline diary period, a mean voided volume $\leq 350 \mathrm{~mL}$, and a postvoid residual volume $\leq 250 \mathrm{~mL}$. One gram of OTG or placebo was applied daily to rotating sites on the abdomen, upper arms/shoulders, or thighs for 12 weeks. Daily incontinence episodes were recorded by the patient in a bladder diary, which was reviewed by the investigator at baseline and at each study visit scheduled 1 , 4,8 , and 12 weeks after treatment initiation.

\section{Analyses}

In this post hoc analysis, changes from baseline in daily incontinence episodes were analyzed separately for patients with an average of 2-3 incontinence episodes/day (moderate incontinence) and those with more than three incontinence episodes/day (severe incontinence) at baseline. Analyzed data were from randomly assigned patients with at least two incontinence episodes/day at baseline who received at least one dose of OTG. Participants with fewer than two incontinence episodes/day were not included in the present analysis because of the small sample size $(n=62)$. Analyses for all time points were based on observed cases. In addition, the last observation carried forward method was used to evaluate treatment effects at study end. Differences between treatment groups in absolute changes in the number of daily incontinence episodes were evaluated by analysis of covariance. Differences between treatment groups in percentage changes in the number of daily incontinence episodes were evaluated by analysis of variance. Percentages of patients in the OTG and placebo groups who achieved complete continence at study end were compared using Chi-square tests.

\section{Results \\ Study population}

Of 789 study participants, 171 had an average of 2-3 incontinence episodes/day (moderate incontinence) and 556 had more than three incontinence episodes/day (severe incontinence, Table 1). Most participants were female and most participants were white. Participants with severe incontinence were slightly older overall than those with moderate incontinence. The mean number of average daily incontinence episodes at baseline among participants with severe incontinence was 6.7 in both treatment groups (Table 1).

\section{Reduction in number of daily incontinence episodes}

Observed changes from baseline in the number of daily incontinence episodes over the course of the study for the two analysis groups are shown in Figure 1. At study end, the absolute decrease in number of daily incontinence episodes was greater in patients with a greater number of incontinence episodes at baseline, both in those who received OTG and in those who received placebo (Table 2). In patients with two to three incontinence episodes/day at baseline, mean change from baseline to study end in the number of daily incontinence episodes was -1.7 for OTG and -1.2 for placebo. In patients with more than three incontinence episodes/day at baseline, mean change from baseline to study end was -3.6 for OTG and -3.1 for placebo. In both analysis groups, the difference between OTG and placebo in absolute change in the number of daily incontinence episodes from baseline to study end was -0.5 (Table 2 ).

Differences between OTG and placebo in the absolute decrease in number of daily incontinence episodes were statistically significant by week 4 of treatment in both analysis groups (Figure 1). Differences between treatments in percentage change from baseline to study end also were statistically significant for both analysis groups $(P<0.05$; Table 2$)$.

\section{Achievement of complete continence}

The proportion of patients with moderate incontinence who achieved complete continence was significantly greater for 
Table I Baseline demographic and clinical characteristics

\begin{tabular}{|c|c|c|c|c|}
\hline \multirow[t]{2}{*}{ Characteristic } & \multicolumn{2}{|c|}{ 2-3 IEs/day at baseline } & \multicolumn{2}{|c|}{$>3$ IEs/day at baseline } \\
\hline & OTG $(n=85)$ & Placebo $(n=86)$ & OTG $(n=276)$ & Placebo $(n=280)$ \\
\hline \multicolumn{5}{|l|}{ Gender, n (\%) } \\
\hline Female & $75(88.2)$ & $70(81.4)$ & $252(91.3)$ & $255(91.1)$ \\
\hline Male & $10(11.8)$ & $16(18.6)$ & $24(8.7)$ & $25(8.9)$ \\
\hline \multicolumn{5}{|l|}{ Age, years } \\
\hline Mean \pm SD & $63.3 \pm 11.0$ & $60.5 \pm 11.6$ & $58.1 \pm 12.6$ & $58.7 \pm 12.3$ \\
\hline Median (range) & $62.0(39.0,83.0)$ & $60.5(25.0,84.0)$ & $59.0(18.0,88.0)$ & $59.0(25.0,84.0)$ \\
\hline \multicolumn{5}{|l|}{ Race, n (\%) } \\
\hline White & $80(94.1)$ & $74(86.0)$ & $242(87.7)$ & $233(83.2)$ \\
\hline Black or African American & $2(2.4)$ & II (I2.8) & $29(10.5)$ & $38(13.6)$ \\
\hline Asian & $3(3.5)$ & I (I.2) & $2(0.7)$ & $5(1.8)$ \\
\hline Other & 0 & 0 & $3(1.1)$ & $4(1.4)$ \\
\hline \multicolumn{5}{|c|}{ No. of daily incontinence episodes } \\
\hline Mean \pm SD & $2.4 \pm 0.4$ & $2.5 \pm 0.4$ & $6.7 \pm 3.0$ & $6.7 \pm 3.0$ \\
\hline Median (range) & $2.3(2.0,3.0)$ & $2.5(2.0,3.0)$ & $6.0(3.3,21.3)$ & $6.0(3.3,19.7)$ \\
\hline \multicolumn{5}{|c|}{ No. of daily urinary frequency events } \\
\hline Mean \pm SD & $1 \mathrm{I} .4 \pm 3.3$ & $11.3 \pm 3.1$ & $12.9 \pm 3.3$ & $12.7 \pm 3.4$ \\
\hline Median (range) & $10.3(8.0,24.0)$ & I0.3 (7.7, 20.7) & I2.3 (8.0, 28.0) & I2.0 (7.7, 26.0) \\
\hline \multicolumn{5}{|l|}{ Voided urinary volume $(\mathrm{mL})$} \\
\hline Mean \pm SD & $177.4 \pm 62.9$ & $17 \mid .5 \pm 58.8$ & $156.8 \pm 65.5$ & $165.7 \pm 70.8$ \\
\hline Median (range) & $179.6(56.6,348.1)$ & $166.2(67.9,342.4)$ & $150.0(7.3,34 \mid .7)$ & I57.6 $(2.7,355.0)$ \\
\hline \multicolumn{5}{|l|}{ No. of daily nocturia events } \\
\hline Mean \pm SD & $1.9 \pm 1.5$ & $2.2 \pm 1.4$ & $2.7 \pm 1.6$ & $2.6 \pm 1.8$ \\
\hline Median (range) & $2.0(0,8.7)$ & $2.0(0,6.7)$ & $2.3(0,11.0)$ & $2.3(0,12.7)$ \\
\hline
\end{tabular}

Abbreviations: IE, incontinence episode; OAB, overactive bladder; OTG, oxybutynin chloride topical gel; SD, standard deviation.

those who received OTG than for those who received placebo $(P<0.01 ;$ Figure 2$)$. Among patients with two to three daily incontinence episodes at baseline, approximately half of those who received OTG and a quarter of those who received placebo achieved complete continence. The proportion of patients with more than three daily incontinence episodes at baseline who achieved complete continence also was greater for those treated with OTG than those who received placebo (Figure 2).

\section{Discussion}

The results of this post hoc analysis demonstrated that OTG compared with placebo significantly reduced the number of daily incontinence episodes irrespective of the severity of incontinence at baseline. Improvement with OTG versus placebo was statistically significant at week 4 and at all subsequent time points of the 12 -week study period. The absolute improvement in urinary continence (ie, change from baseline in the number of daily incontinence episodes) was clearly related to the severity of continence at baseline, but differences in improvement between patients with moderate incontinence and those with severe incontinence were essentially the result of differences in the size of the placebo effect. Thus, the placebo-adjusted treatment effect (ie, the numerical difference between the mean decrease in the number of incontinence episodes achieved with OTG and the corresponding mean decrease achieved with placebo) was the same in the two analysis groups $(-0.5$ incontinence episodes/day).

Among patients with moderate incontinence at baseline, those who received OTG were approximately twice as likely to achieve continence as those who received placebo, and the difference was statistically significant. The percentage of patients with severe incontinence at baseline who achieved complete continence was higher for OTG than placebo, but the difference was not statistically significant. Patients with severe incontinence at baseline overall were less likely to achieve complete urinary continence with OTG than were patients with moderate incontinence. However, comparison of percentage changes from baseline between patients treated with OTG and those who received placebo demonstrated that OTG provided significant symptom improvement relative to baseline levels even in patients with severe symptoms at baseline (ie, with a median of 6.0 incontinence episodes/day).

Overall, our findings are consistent with retrospective studies of other antimuscarinic agents. An analysis of data from a 12-week, randomized, double-blind, placebo-controlled 

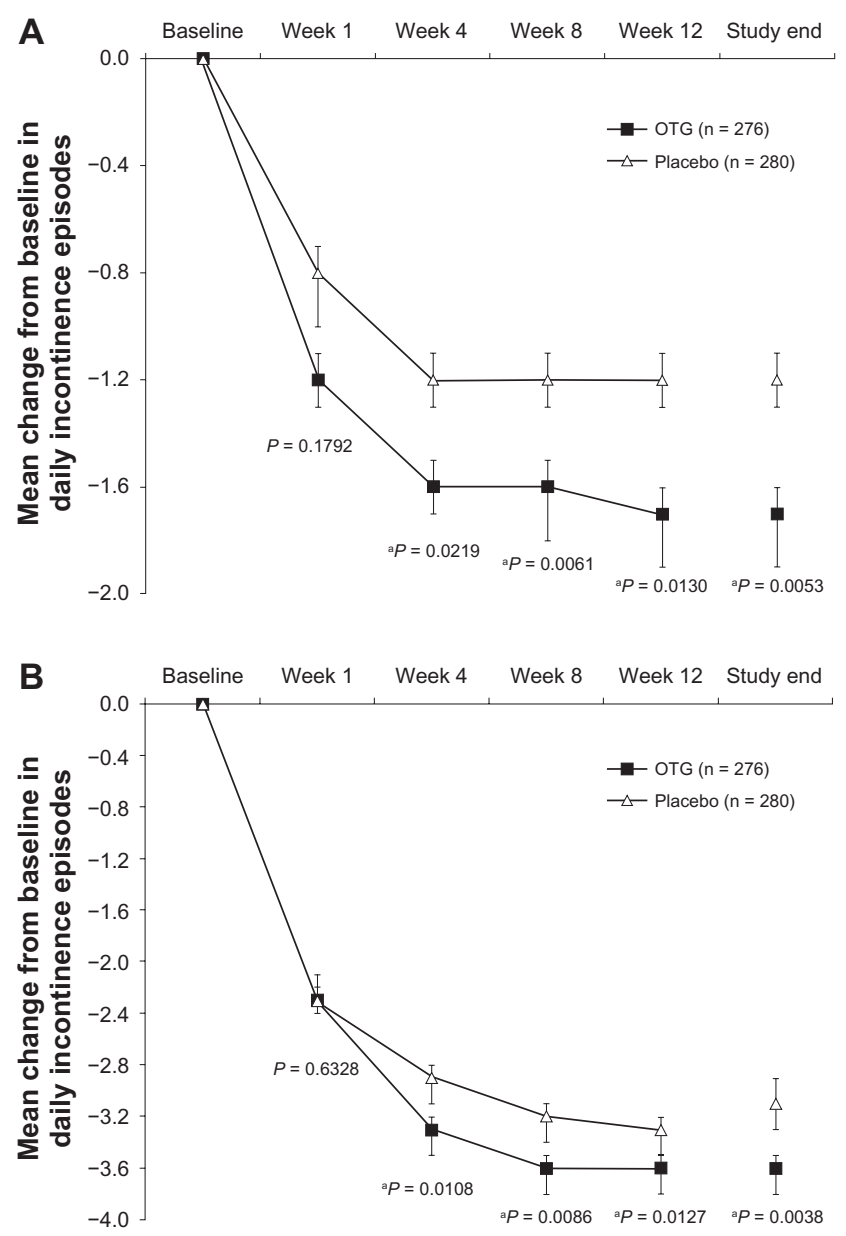

Figure I Change from baseline over time in daily urinary incontinence episodes for patients with (A) moderate incontinence (2-3 urinary incontinence episodes/ day) and (B) severe incontinence ( $>3$ urinary incontinence episodes/day) at baseline. Error bars indicate $95 \%$ confidence intervals. $P$ values were derived from analysis of covariance.

Note: ap $<0.05$. Last observations carried forward for study end. Observed cases for all other time points.

Abbreviation: OTG, oxybutynin chloride topical gel. study of tolterodine extended-release found that mean reductions in weekly urinary incontinence episodes (ie, absolute improvement, not placebo-adjusted) increased with baseline incontinence severity $(1-6,7-13,14-20$, and $\geq 21$ incontinence episodes/week) for patients treated with tolterodine extended-release. ${ }^{6}$ Similar to the results of our analysis, rates for achievement of total dryness (ie, complete continence) with tolterodine extended-release decreased with increasing frequency of urinary incontinence episodes at baseline. Dryness rate for tolterodine extended-release was $31 \%$ (placebo, 24\%) among patients with 7-13 incontinence episodes/week at baseline and 19\% (placebo, 8\%) for patients with $\geq 21$ incontinence episodes/week at baseline. ${ }^{6}$ The degree of incontinence severity at baseline also has been shown to affect the proportion of patients with overactive bladder who achieve continence with a fixed dose $(60 \mathrm{mg} /$ day) of trospium chloride extended-release. ${ }^{9}$ Among patients with an average of $>1.0-2.0$ urgency urinary incontinence episodes per day, $48 \%$ of those treated with trospium chloride extended-release compared with $29 \%$ of those who received placebo achieved complete continence after 12 weeks of treatment. In contrast, the continence achievement rate among patients with more than five urgency urinary incontinence episodes at baseline was only slightly greater for trospium chloride extended-release (18.5\%) than placebo (15.4\%). Logistic regression analysis further showed a highly significant $(P=0.0001)$ inverse correlation between continence achievement rate and baseline incontinence severity. ${ }^{9}$

Results of a retrospective analysis of data from the Solifenacin and Tolterodine extended-release as an Active comparator in a Randomised (STAR) trial ${ }^{10}$ showed that

Table 2 Change from baseline to study end in the number of daily urinary incontinence episodes

\begin{tabular}{|c|c|c|c|c|}
\hline & \multicolumn{2}{|c|}{ 2-3 IEs/day at baseline } & \multicolumn{2}{|c|}{$>3$ IEs/day at baseline } \\
\hline & OTG $(n=85)$ & Placebo $(n=86)$ & OTG $(n=276)$ & Placebo $(n=280)$ \\
\hline \multicolumn{5}{|l|}{ Study end } \\
\hline Mean \pm SD & $0.7 \pm 1.3$ & $1.3 \pm 1.2$ & $3.1 \pm 3.6$ & $3.6 \pm 3.6$ \\
\hline Median & 0.3 & 1.0 & 2.0 & 2.7 \\
\hline \multicolumn{5}{|c|}{ Absolute change } \\
\hline Mean \pm SD & $-1.7 \pm 1.4$ & $-1.2 \pm 1.3$ & $-3.6 \pm 3.0$ & $-3.1 \pm 3.4$ \\
\hline Median & -2.0 & -1.3 & -3.3 & -3.0 \\
\hline$P$ value $^{\mathrm{a}}$ & \multicolumn{2}{|c|}{0.0053} & \multicolumn{2}{|c|}{0.0038} \\
\hline \multicolumn{5}{|l|}{ Change, \% } \\
\hline Mean \pm SD & $-68.7 \pm 54.7$ & $-49.1 \pm 49.1$ & $-56.6 \pm 40.5$ & $-46.9 \pm 43.0$ \\
\hline Median & -88.9 & -62.5 & -66.7 & -50.0 \\
\hline$P$ value $\mathrm{b}^{\mathrm{b}}$ & \multicolumn{2}{|c|}{0.0148} & \multicolumn{2}{|c|}{0.0062} \\
\hline
\end{tabular}

Notes: ${ }^{a} P$ values were derived from analysis of covariance; ${ }^{b} P$ values were derived from analysis of variance.

Abbreviations: IE, incontinence episode; OTG, oxybutynin chloride topical gel; SD, standard deviation. 


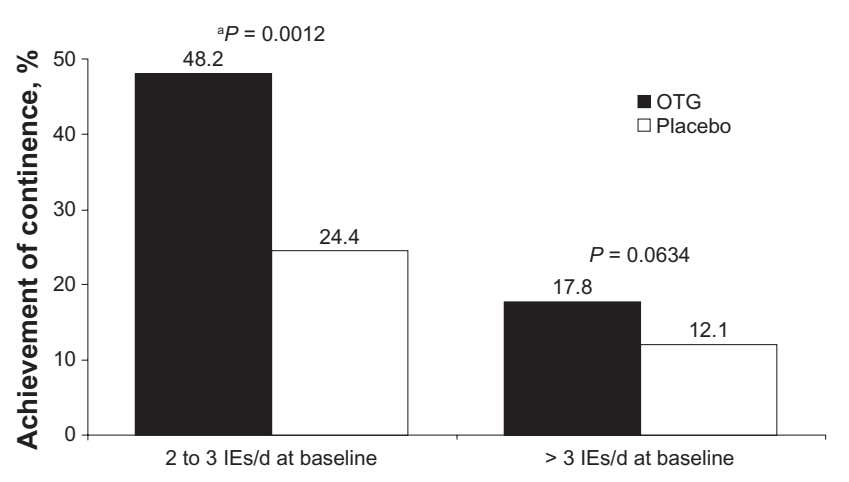

Figure 2 Percentage of patients achieving complete continence at study end. $P$ values were derived from $C$ hi-square test.

Note: ${ }^{\text {a }} P<0.05$

Abbreviations: IE, incontinence episode; OTG, oxybutynin chloride topical gel.

overactive bladder patients with more severe symptoms were more likely to request dose increases and that such dose increases improved patient satisfaction. ${ }^{11}$ Another retrospective study found that increasing the dose of darifenacin from $7.5 \mathrm{mg}$ to $15 \mathrm{mg}$ did not affect median percentage reduction from baseline in incontinence episodes among patients with mild or moderate overactive bladder symptoms but increased median percentage reduction in incontinence episodes from $50 \%$ to $71 \%$ among patients with severe symptoms (defined as $\geq 21$ incontinence episodes/week). ${ }^{7}$ Similar findings from a post hoc analysis of data from two clinical studies of fesoterodine showed that, in overactive bladder patients with an average of two to four daily urgency urinary incontinence episodes (exclusive) and those with at least four daily urgency urinary incontinence episodes, fesoterodine $8 \mathrm{mg}$ compared with fesoterodine $4 \mathrm{mg}$ provided significantly greater mean reductions in the number of urgency urinary incontinence episodes $(P<0.05){ }^{10,12}$

The present study has several limitations. Our analysis was retrospective and only evaluated the effect of incontinence severity at baseline on OTG-mediated improvement in continence. Effects on other urinary symptoms of overactive bladder, such as urgency and frequency, were not evaluated. Furthermore, patients with mild incontinence (less than two incontinence episodes/day) at baseline were excluded from the present analysis because they constituted a relatively small group with low statistical power.

In summary, treatment with OTG significantly improved continence regardless of the severity of incontinence at baseline. The results of this analysis suggest that the treatment benefit of OTG that patients can receive in terms of absolute change in incontinence episodes per day is independent of the severity of incontinence at the beginning of therapy. In addition, although patients with less severe incontinence are more likely to achieve complete continence, our findings demonstrate that OTG also provides significant benefits in terms of percentage symptom improvement, even for patients with severe incontinence.

\section{Acknowlegment}

This study and editorial assistance of this article were funded by Watson Pharma, Inc. Editorial assistance was provided by Scientific Connexions, Newtown, PA, USA.

\section{Disclosure}

PKS is an advisor and lecturer for Allergan, Astellas, GlaxoSmithKline, Ortho, Pfizer, and Watson, and is an investigator for Allergan, Ortho, Pfizer, and Watson. SAM is an advisor and lecturer for Allergan, Astellas, Pfizer, and Watson. HT, $\mathrm{KEC}$, and $\mathrm{GH}$ are employees of Watson.

\section{References}

1. Haylen BT, De Ridder D, Freeman RM, et al. An International Urogynecological Association (IUGA)/International Continence Society (ICS) joint report on the terminology for female pelvic floor dysfunction. Int Urogynecol J Pelvic Floor Dysfunct. 2010;21(1):5-26.

2. Stewart WF, Van Rooyen JB, Cundiff GW, et al. Prevalence and burden of overactive bladder in the United States. World J Urol. 2003;20(6):327-336.

3. Coyne KS, Sexton CC, Irwin DE, Kopp ZS, Kelleher CJ, Milsom I. The impact of overactive bladder, incontinence and other lower urinary tract symptoms on quality of life, work productivity, sexuality and emotional well-being in men and women: results from the EPIC study. BJU Int. 2008;101(11):1388-1395.

4. Appell RA. Pharmacotherapy for overactive bladder: an evidencebased approach to selecting an antimuscarinic agent. Drugs. 2006;66(10):1361-1370.

5. Staskin DR, Dmochowski RR, Sand PK, et al. Efficacy and safety of oxybutynin chloride topical gel for overactive bladder: a randomized, double-blind, placebo controlled, multicenter study. J Urol. 2009;181(4):1764-1772.

6. Wein AJ, Khullar V, Wang JT, Guan Z. Achieving continence with antimuscarinic therapy for overactive bladder: effects of baseline incontinence severity and bladder diary duration. BJU Int. 2007;99(2):360-363.

7. Dmochowski RR, Larson-Peters A, Aronstein WS, Seifu Y. Efficacy of darifenacin in patients with varying baseline symptom severity. UroToday Int J. 2009;2(3):1944-5784.

8. Coyne KS, Matza LS, Kopp Z, Abrams P. The validation of the patient perception of bladder condition (PPBC): a single-item global measure for patients with overactive bladder. Eur Urol. 2006;49(6): $1079-1086$.

9. Staskin DR, Cardozo L. Baseline incontinence severity is predictive of the percentage of patients continent after receiving once-daily trospium chloride extended release. Int J Clin Pract. 2009;63(6):973-976.

10. Chapple C, Fiala R, Gorilovsky L, et al. The STAR study: Analysis of symptom severity and treatment response in overactive bladder. Presented at the 21st Annual European Association of Urology Congress, April 5-8, 2006, Paris, France. Available at: http://www. uroweb.org/publications/eau-abstracts-online//?AID=8914. Accessed June 16, 2010. 
11. Chapple CR, Martinez-Garcia R, Selvaggi L, et al. A comparison of the efficacy and tolerability of solifenacin succinate and extended release tolterodine at treating overactive bladder syndrome: results of the STAR trial. Eur Urol. 2005;48(3):464-470.
12. Cardozo L, Khullar V, Wang JT, Guan Z, Sand PK. Fesoterodine in patients with overactive bladder syndrome: can the severity of baseline urgency urinary incontinence predict dosing requirement? BJU Int. 2010;106(6):816-821.

\section{Publish your work in this journal}

The Open Access Journal of Urology is an international, peer-reviewed, open access journal publishing original research, reports, editorials, reviews and commentaries on all aspects of adult and pediatric urology in the clinic and laboratory including the following topics: Pathology, pathophysiology of urological disease; Investigation and treatment of urological disease; Pharmacology of drugs used for the treatment of urological disease. The manuscript management system is completely online and includes a very quick and fair peer-review system, which is all easy to use. Visit http://www.dovepress.com/testimonials.php to read real quotes from published authors.

Submit your manuscript here: http://www.dovepress.com/open-access-journal-of-urology-journal 